\title{
Gaining competence in needle-knife fistulotomy - can I begin on my own?
}

Authors

Institutions
Luís Lopes ${ }^{1,2,3}$, Mário Dinis-Ribeiro ${ }^{4,5}$, Carla Rolanda ${ }^{2,3,6}$

Institutions are listed at the end of article. submitted 14. April 2015 accepted after revision 4. November 2015

\section{Bibliography}

Dol http://dx.doi.org/ 10.1055/s-0041-109399 Published online: 15.1.2016 Endoscopy International Open 2016; 04: E383-E388

(c) Georg Thieme Verlag KG Stuttgart · New York E-ISSN 2196-9736

\section{Corresponding author} Luis Lopes, MD PhD Hospital de Santa Luzia, Department of Gastroenterology Unidade Local de Saúde do Alto Minho

Estrada de Santa Luzia 4901-858

Viana do Castelo Portugal

Fax: +351-252-802577

luis.m.lopes@me.com
Background: While there are guidelines for appropriate training in ERCP, these are non-existent for needle-knife precut. The aim of this study was: (1) evaluate the experience curve of three endoscopists in needle-knife fistulotomy (NKF); (2) propose a minimum number of NKF procedures to attest proficiency.

Methods: Between November 1997 and March 2011, the first 120 consecutive NKF performed by three endoscopists (A, B, and C) were selected (360 patients) from three centers. Each group of 120 patients was chronologically ordered into three subgroups of 40 . The main outcomes were: NKF use, NKF success, and post-ERCP adverse events.

Results: The need for NKF did not decrease over time. The NKF success rate in the first attempt for

\section{Introduction \\ $\nabla$}

The need to decrease costs in all healthcare systems has brought quality measurement to the forefront of modern medicine, endoscopy included $[1,2]$. High value endoscopy is positively correlated with an adequate training program $[3,4]$. Concerning endoscopic retrograde cholangiopancreatography (ERCP), the selective cannulation of the common bile duct (CBD) is one of the most demanding maneuvers that an interventional endoscopist is required to master $[1,2]$. Even among experienced endoscopists, biliary cannulation is unsuccessful in between $15 \%$ and $30 \%$ of cases, when only conventional methods are employed [3-6]. A sustainable cannulation rate above $90 \%$ implies the performance of alternative techniques of access, such as the precut. This rescue strategy consists of the incision of the papilla to facilitate access to the CBD $[1,7]$. Precut, in particular, needle-knife fistulotomy (NKF), increases the yield of cannulation and appears to be safe, when performed by experienced endoscopists $[8,9]$. endoscopist $A$ and $C$ in each of the three subgroups was $85 \% / 85 \%, 87.5 \% / 87.5 \%$, and $87.5 \% /$ $90 \%$, respectively. Furthermore, both demonstrated a high NKF success in their initial 20 NKFs (85\% and $80 \%$, respectively). Endoscopist B however presented a different pattern as the success rate initiated at $60 \%$, then rose to $82.5 \%$ and $85 \%$ for the last group $(P=0.03)$. Adverse events were mild (28 of the 32 occurrences) with no clear reduction with increased experience.

Conclusions: A skillful endoscopist may expect to master NKF easily with few adverse events. While some endoscopists could begin on their own because of their innate skills, a minimal training is needed for all, as we cannot predict skills in advance. We propose a minimum of 20 NKF precuts to attest a trainee's competence in this procedure.

Recent studies support a trend to its early implementation in the cannulation algorithm, as a process to optimize its safety profile and decrease the overall duration of the ERCP [10]. Given the potential usefulness, a question immediately arises as to how to achieve competency in this procedure. Until now, no national or international recommendations have been issued with regard to how much training is necessary for an endoscopist to achieve technical proficiency in performing precut techniques [11]. Although in ERCP it is suggested that a trainee should perform a minimum of 200 procedures to achieve competency, the learning curve associated with NKF is uncertain $[12,13]$. Given the huge difficulties in performing a large prospective study, due to time constrains (several years of follow-up required) and a limited number of endoscopists performing the technique on a regular basis in order to achieve an adequate sample size, insights from the reported experience of skilled endoscopists are valuable to support expert-based considerations/recommendations. Unfortunately, only a few articles have been published, all of which are 
single endoscopist reports, with some divergent conclusions [11, $14-17]$. Two of these articles point to the need for further studies with multiple operators. The aim of this study was to evaluate the use, success, and adverse events of needle-knife fistulotomy (NKF) over time and to establish a minimum number of NKF procedures to acquire competence. It is the largest cohort reported to date and the first to include three operators.

\section{Materials and methods \\ $\nabla$}

Study design, selection of participants and operators

This retrospective cohort study was carried out with the workload of three experienced endoscopists (>200 ERCPs/year) in three referral centers for ERCP in Portugal. All patients with naive papilla undergoing an NKF during an ERCP for a biliary indication were eligible for this study. Exclusion criteria were surgically altered gastroduodenal anatomy, abnormal coagulation tests, and tumors of the papilla. For the study purpose, the first 120 consecutive patients submitted to NKF by each endoscopist were selected. The 120 patients were chronologically divided into three groups of 40: group 1 (1st to 40th), group 2 (41st to 80th) and group 3 (81st to 120th). The enrollment period occurred between: November 2006 and December 2010 for Endoscopist A (EA), November 2006 and March 2011 for Endoscopist B (EB), and November 1997 and December 2001 for Endoscopist C (EC). All three endoscopists had previous formal training in ERCP, but only EA had exposure to NKF during his training program, which did not include hands-on experience. EA performed part of his program under the supervision of EC. EB and EC had no exposure to NKF in their training period. All three began performing the procedure (NKF) in their hospitals without any specific supervision or previous hands-on training, EA and EC in the first year after training, while EB only performed his first NKF 10 years after training.

All patients gave written consent for the procedure and the ethics committees of the institutions approved the study.

\section{ERCP and biliary cannulation algorithm}

All patients were prepared and sedated (by an anesthesiologist) as standard medical practice. The three endoscopists used a therapeutic videoduodenoscope in all of the ERCPs performed (EA and EB: TJF 160 VR, Olympus Corporation, Melville, New York, United States; EC: Pentax 3440T, Pentax Corporation, Hamburg, Germany). If deep biliary cannulation was not successful using a standard technique within a time frame of 12 to $15 \mathrm{~min}$, a NFK was performed using a needle knife (presented as first attempt). After the ERCP was completed, all patients were admitted for observation, for at least $24 \mathrm{~h}$ before discharge. Whenever the endoscopists failed a deep cannulation of the biliary duct, a second ERCP was scheduled 7-14 days later and performed when possible (presented as global attempt). Prophylaxis of post-ERCP pancreatitis (either with the use of a pancreatic stent or with medication) was not used in any of the patients studied. ERCP was not performed on suspected sphincter of Oddi dysfunction (SOD) type II or III patients.

\section{Standard biliary cannulation}

Selective cannulation of the bile duct was initially attempted by EA and EB with a triple lumen sphincterotome (Ultratome XL, Boston Scientific, Natick, Massachusetts, United States), preloaded with contrast and a guidewire (Jagwire, Boston Scientific), and by EC with a double lumen sphincterotome (Ultratome, Boston Scientific), preloaded with contrast. If biliary cannulation was not achieved using this equipment, a different biliary catheter or guidewire could be used at the discretion of the endoscopist.

\section{Needle-knife fistulotomy}

NFK was performed using a needle knife (EA, EB and EC: Olympus KD-11Q Olympus Corporation) with electrosurgical current in the endocut mode (EA and EB: Olympus-PSD 60, Olympus Corporation; EC: ICC200, ERBE, Electromedizin GmbH, Tubingen, Germany).

The NKF procedure was performed by making a puncture in the papilla above the orifice, and then cutting along an 11 o'clock axis either upward or downward, depending on where the incision started in the papillary mound, while maintaining at least a $3 \mathrm{~mm}$ free distance from the papillary orifice. The cut was slowly extended until the muscle of the intraduodenal portion of the CBD was exposed; then a small cut was performed in the muscle with the needle knife, creating a fistula. The cannulation of the bile duct was performed directly with the closed needle knife, if it slipped easily up, or, in a minority of cases, after gently probing the fistula with a preloaded wire in a papillotome.

The selective cannulation was confirmed by the injection of a low-osmolality non-ionic radiological contrast (Ultravist, Iopromide, Bayer Schering Pharma, Berlin, Germany) and the needle knife was exchanged over the wire for the sphincterotome. After deep cannulation was achieved, a cholangiogram was taken. If necessary, the sphincterotomy was extended with a standard sphincterotome (usually until the limit of the papillary mound) in the endocut mode and the necessary maneuvers were performed.

\section{Variables and data collection}

Data were prospectively collected by the endoscopists in a detailed form following each ERCP and subsequently registered in the unit's endoscopic database. The database included: demographic data, indications, anatomic abnormalities, biliary/pancreatic cannulation, biliary access technique, diagnosis, therapeutic procedures, intraprocedural and post-ERCP adverse events (AE). Post-procedural AE (30-day follow-up) were retrospectively collected (research nurse). Intraprocedural and post-procedural adverse events were defined and graded according to guidelines established by Cotton et al. [18].

\section{Statistical analysis}

This was performed using the software package IBM SPSS Statistics version 20.0.0. Interval variables were summarized using the mean and standard deviation and nominal/ordinal variables using proportions. Age, sex, indications, rate of NKF utilization, success in cannulation (first attempt and global), and occurrence of adverse events were compared between the different groups for each endoscopist. Differences between groups were tested using Pearson's chi-squared test or Fisher's exact test for categorical data, whereas continuous variables were analyzed using non-parametric tests (Kruskal-Wallis and Mann-Whitney $U$ test). A $P$ value of less than 0.05 was considered statistically significant. 
Table 1 Demographics and clinical indications.

\begin{tabular}{|c|c|c|c|c|c|c|c|c|c|c|}
\hline & \multicolumn{3}{|c|}{ Endoscopist A } & \multicolumn{3}{|c|}{ Endoscopist B } & \multicolumn{4}{|c|}{ Endoscopist C } \\
\hline & $\begin{array}{l}\text { Group } 1 \\
\mathbf{N}(\%)\end{array}$ & $\begin{array}{l}\text { Group } 2 \\
\mathrm{~N}(\%)\end{array}$ & $\begin{array}{l}\text { Group } 3 \\
\mathrm{~N}(\%)\end{array}$ & $\begin{array}{l}\text { Group } 1 \\
\text { N (\%) }\end{array}$ & $\begin{array}{l}\text { Group } 2 \\
\mathrm{~N}(\%)\end{array}$ & $\begin{array}{l}\text { Group } 3 \\
\mathrm{~N}(\%)\end{array}$ & $\begin{array}{l}\text { Group } 1 \\
\mathbf{N}(\%)\end{array}$ & $\begin{array}{l}\text { Group } 2 \\
\mathrm{~N}(\%)\end{array}$ & $\begin{array}{l}\text { Group } 3 \\
\mathrm{~N}(\%)\end{array}$ & $P$ value $^{1}$ \\
\hline \multicolumn{11}{|l|}{ Demographics } \\
\hline Sex (\% female) & $25(62.5)$ & $23(57.5)$ & $22(55)$ & $24(60)$ & $21(52.5)$ & $23(57.5)$ & $23(57.5)$ & $24(60)$ & $21(52.5)$ & 0.88 \\
\hline Age [mean (SD)] & $\begin{array}{l}68.5 \\
(13.9)\end{array}$ & $\begin{array}{l}66.4 \\
(15.4)\end{array}$ & $65.9(17)$ & $\begin{array}{l}69.2 \\
(14.1)\end{array}$ & $68.2(17)$ & $66.8(14)$ & $\begin{array}{l}69.5 \\
(15.9)\end{array}$ & $\begin{array}{l}64.4 \\
(18.4)\end{array}$ & $\begin{array}{l}69.9 \\
(17.2)\end{array}$ & 0.89 \\
\hline No. of ERCPs (\% NKF) & $\begin{array}{l}220 \\
(18.2)\end{array}$ & $\begin{array}{l}201 \\
(19.9)\end{array}$ & $\begin{array}{l}212 \\
(18.8)\end{array}$ & $\begin{array}{l}265 \\
(15.1)\end{array}$ & $\begin{array}{l}198 \\
(20.2)\end{array}$ & $\begin{array}{l}220 \\
(16.7)\end{array}$ & $298(13.4)$ & $232(17.2)$ & $\begin{array}{l}240 \\
(16.7)\end{array}$ & 0.46 \\
\hline \multicolumn{11}{|l|}{ Indications } \\
\hline Jaundice & $13(32.5)$ & $15(37.5)$ & $14(35)$ & $14(35)$ & $12(30)$ & $12(30)$ & $18(45)$ & $16(40)$ & $15(37.5)$ & 0.75 \\
\hline Choledocholithiasis & $15(37.5)$ & $12(30)$ & $13(32.5)$ & $17(42.5)$ & $12(30)$ & $13(32.5)$ & $12(30)$ & $14(35)$ & $16(40)$ & 0.75 \\
\hline $\begin{array}{l}\text { Biliary/pancreatic } \\
\text { cancer }\end{array}$ & $5(12.5)$ & $3(7.5)$ & $4(10)$ & $1(2.5)$ & $5(12.5)$ & $4(10)$ & $5(12.5)$ & $4(10)$ & $4(10)$ & 0.75 \\
\hline Dilated CBD & $3(7.5)$ & $8(20)$ & $3(7.5)$ & $3(7.5)$ & $4(10)$ & $6(15)$ & $3(7.5)$ & $2(5)$ & $1(2.5)$ & 0.75 \\
\hline Injuries & $3(7.5)$ & $2(5)$ & $2(5)$ & $2(5)$ & $2(5)$ & $2(5)$ & $1(2.5)$ & $2(5)$ & $2(5)$ & 0.75 \\
\hline Others & $1(2.5)$ & $2(0)$ & $4(10)$ & $3(7.5)$ & $5(12.5)$ & $3(7.5)$ & $1(2.5)$ & $2(5)$ & $2(5)$ & 0.75 \\
\hline
\end{tabular}

$1 P<0.05$.

\begin{tabular}{|llllll|}
\hline Endoscopist & Attempts & $\begin{array}{l}\text { Group } \mathbf{1} \\
\mathbf{N}(\%)\end{array}$ & $\begin{array}{l}\text { Group 2 } \\
\mathbf{N}(\%)\end{array}$ & $\begin{array}{l}\text { Group 3 } \\
\text { N (\%) }\end{array}$ & P value \\
\hline Cannulation & First & $34(85)$ & $35(87.5)$ & $35(87.5)$ & 0.95 \\
\hline Endoscopist A & Global & $37(92.5)$ & $38(95)$ & $38(95)$ & 0.47 \\
\hline & First & $24(60)$ & $33(82.5)$ & $34(85)$ & $0.03^{1}$ \\
\hline Endoscopist B & Global & $33(82.5)$ & $35(87.5)$ & $36(90)$ & 0.68 \\
\hline Endoscopist C & First & $34(85)$ & $35(87.5)$ & $36(90)$ & 0.42 \\
\hline & Global & $38(95)$ & $36(90)$ & $37(92.5)$ & 0.76 \\
\hline Complications & & & & & \\
\hline Endoscopist A & Overall & $4(10)$ & $2(5)$ & $4(10)$ & 0.79 \\
\hline & Pancreatitis & $4(10)$ & $2(5)$ & $2 \mathrm{a}(5)$ & 0.43 \\
\hline & Bleeding & $0(0)$ & $0(0)$ & $2(5)$ & 0.26 \\
\hline Endoscopist B & Overall & $2(5)$ & $4(10)$ & $3(7.5)$ & 0.32 \\
\hline & Pancreatitis & $2(5)$ & $3 \mathrm{a}(7.5)$ & $2(5)$ & 0.68 \\
\hline Endoscopist C & Bleeding & $0(0)$ & $1(2.5)$ & $0(0)$ & 0.81 \\
\hline & Overall & $4(10)$ & $4(10)$ & $5(12.5)$ & 0.56 \\
\hline & Pancreatitis & $3 \mathrm{a}(7.5)$ & $4(10)$ & $4(10)$ & 0.58 \\
\hline & Bleeding & $1(2.5)$ & $0(0)$ & $1 \mathrm{~b}(2.5)$ & 0.68 \\
\hline
\end{tabular}

$1 P<0.05$.

${ }^{2}$ All mild complications, except: ${ }^{\mathrm{a}} 1$ moderate and ${ }^{\mathrm{b}} 1$ severe

\section{Results}

$\boldsymbol{\nabla}$

\section{Procedures}

The number of ERCPs performed by the three endoscopists during the enrollment period totaled: $\mathrm{EA}=853$ (50 months), $\mathrm{EB}=920$ (53 months), and $\mathrm{EC}=1038$ (50 months). From these groups, the number of patients with naive papilla were: $\mathrm{EA}=633, \mathrm{~EB}=683$, and $\mathrm{EC}=770$.

\section{Demographics and indications}

All groups presented a higher percentage of women. The mean age varied from a minimum of 64.4 years (EC/Group 2 ) to a maximum of 69.9 years (EC/Group 3). Jaundice and choledocholithiasis were the most common indications for ERCP. No significant differences were observed with regard to age, sex, or indications between groups ( $\bullet$ Table $\mathbf{1}$ ).

\section{NKF use}

The relative frequency of NKF use over the study period for each endoscopist did not exhibit a trend. EA performed NKF as a rescue technique in $18.2 \%$ of the first group, $19.9 \%$ of the second, and $18.9 \%$ of the third group of ERCPs ( $\triangle$ Table 1 ). For EB, NKF rate in the first group was $15.1 \%, 20.2 \%$ in the second, and $16.7 \%$ in the last group.EC performed NKF in $13.4 \%, 17.2 \%$, and $16.7 \%$, respectively ( $\bullet$ Table $\mathbf{1})$.

\section{Cannulation success}

EA's NKF success rate at the first attempt was $85 \%, 87.5 \%$, and $87.5 \%$ for the three groups ( $O$ Table 2 ). EC's rate for the first attempt was similar with $85 \%, 87.5 \%$, and $90 \%$. EB, however, presented a different pattern as the success rate initiated at $60 \%$ for the first group and then rose during the duration of the study to $82.5 \%$ and $85 \%$ for the subsequent groups $(P=0.03)$. The overall cannulation rate for all endoscopists in the last group (Group C) was above $90 \%$. With the exception of the temporal positive 


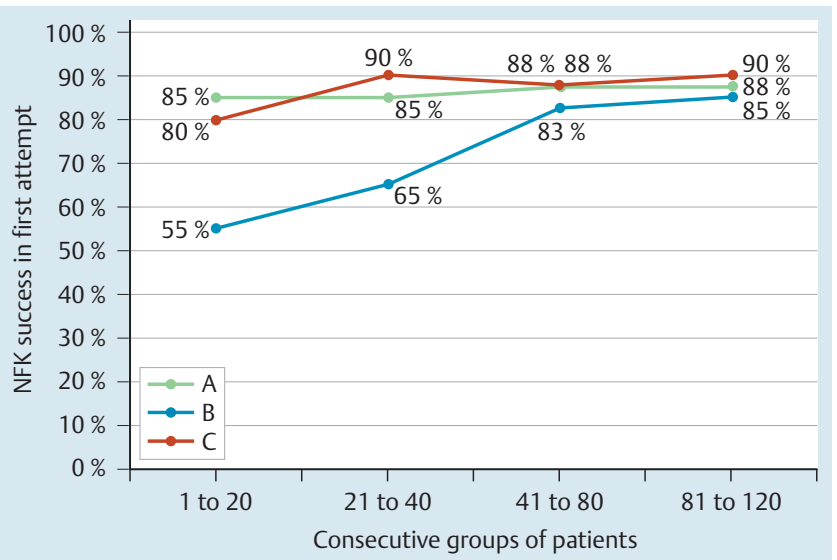

Fig. 1 NKF learning curve.

trend for NKF success for EB, all other differences between groups did not achieve statistical significance ( $\bullet$ Table 2 ).

The first group of 40 patients for each endoscopist was further subdivided into two groups of 20 to evaluate the cannulation success in the early phase of the learning curve ( $\bullet$ Fig.1). The success rate in the initial ERCP for EA and EC was $85 \%$ and $80 \%$, respectively, while for $\mathrm{EB}$ it was $55 \%$.

\section{Adverse events}

AEs related to the procedure were mild (28 out of the 32 occurrences) with no decrease registered over the study period ( $\boldsymbol{O}$ Table2). Pancreatitis was the most common complication; nonetheless, no common apparent trend was registered during the duration of the study. Only one severe case was recorded which was resolved with appropriate treatment. AE exhibited a decrease in the post-ERCP pancreatitis rate from $10 \%$ in the first group to $5 \%$ in the second. The rate of pancreatitis for EB increased from the first group to the second, but then decreased in the third: $5 \%, 7.5 \%$ and $5 \%$. EC presented a different pattern starting off with $7.5 \%$, and then increasing to $10 \%$ in the later groups $(\bullet$ Table 2$)$.

\section{Discussion}

$\nabla$

In recent years, performance measurement in healthcare has become an established practice $[2,19]$. Growing healthcare expenditures and increasing awareness of the various stakeholders have transformed quality into one of the most important dimensions in modern medicine. ERCP is a complex endoscopic procedure established in the management of biliary and pancreatic disorders $[16,20,21]$. In order to assure high-quality endoscopy, the American Society for Gastrointestinal Endoscopy (ASGE) developed several quality indicators for ERCP $[1,2,12,22]$. Quality in ERCP lies in adequate training to learn the necessary technical and cognitive skills. While there are guidelines for appropriate training in ERCP, there are none for NKF $[3,4,11,23]$. Although much has been published with regard to the efficacy and safety of this technique, only five reports have evaluated the learning curve for NKF, all of which relate the experience of single endoscopists $[1,11,14-17]$. This study is unique in that it assesses the learning curve of NKF from three endoscopists, in the largest aggregated cohort of patients published to date.
Siegel et al. reported the first precut papillotomy with a traction papillotome in 1980 [5,6,24]. Subsequently, in 1986, Huibregtse et al. reported a new precut technique, in which the incision of the papillary roof was performed by needle knife $[1,7,25]$. Needle-knife precut papillotomy (either the classic approach or NKF) is the most common option for achieving CBD cannulation during ERCP when endoscopists face difficult biliary cannulation $[8,9,26,27]$. Given its usefulness in the cannulation algorithm, evidence-based data are needed to support recommendations for adequate training.

The data from this study suggest that the effect of number of procedures in the NKF success rate is distinct between endoscopists. EA and EC began with a success rate of over $80 \%$, and the improvement afterwards was minimal. Akaraviputh et al. reported a similar pattern when evaluating the success rate of NKF over four groups of 50 patients $[10,16]$. The NKF volume, on the other hand, had a strong positive effect in the yield of cannulation for EB. There was a significant increase in the cannulation rate from an initial $60 \%$ in the first 40 patients, to $85 \%$ in the last group. Robinson et al. reported a similar pattern with an increase from $68 \%$ to $76 \%$ when comparing the first 50 patients with the subsequent group of $25[11,17]$. Therefore, our results demonstrate that some degree of improvement exists in the cannulation success rate with NKF as procedural experience increases, although this effect might be greater for some operators and smaller or minimal for others.

By combining our results with the results from other studies ( $\bullet$ Table 3), we suggest that technical experience is an important determinant of procedural success for endoscopists with average skill in ERCP who present suboptimal precut cannulation rates (below 70\%) soon after beginning to perform NKF. On the other hand, for those who start with cannulation success rates of $80 \%$ or higher, cumulative volume seems to be a less significant influencing factor and innate technical skills and/or younger age at starting may play an important role in certain cases. The effect of age in the ability to acquire motor skills is an interesting subject for discussion, and although merely speculative, we could argue that the longer learning curve of EB could be related to his older age when he began to perform NKF. It should be highlighted though, that despite the fact that it took longer, the endoscopist was able to learn the skill with excellent results. This can be a topic of future research in other areas of interventional endoscopy, with potential implications in the optimal timing of training.

Harewood et al. reported a decrease in the need for precut over time, suggesting that the procedure appears to decrease with ERCP experience [11-13]. In their report, the rate of NKF decreased from $13 \%$ in the first 385 patients to $9 \%$ in the last 583 patients. Other authors reported distinct conclusions, such as Rollhauser et al. and Fukatsu et al. who reported an increase in precut with ERCP experience [11,14-17]. Our results did not demonstrate a decrease in the use of NKF over time and suggested that each endoscopist tends to maintain a stable baseline level of precut utilization over time. These distinct trends between studies could be explained by personal preferences in the cannulation algorithm, and most importantly by the timing of the precut that each endoscopist considered. Therefore, the proportion of NKF in the total number of biliary attempts should not be interpreted as a surrogate indicator of the cannulation skill of an endoscopist $[20,21,28]$.

The overall post-ERCP adverse events did not demonstrate a decreasing tendency over time. When we look at post-ERCP pancreatitis in particular, the trend is distinct between endoscopists, 
Table 3 Published series about needle-knife precut learning curve (all single endoscopist).

\begin{tabular}{|c|c|c|c|c|c|c|}
\hline Reference & $\begin{array}{l}\text { NKF } \\
\text { (n) }\end{array}$ & $\begin{array}{l}\text { Groups of } \\
\text { patients ( } n \text { ) }\end{array}$ & $\begin{array}{l}\text { Cannulation at first } \\
\text { attempt (\%) }\end{array}$ & $\begin{array}{l}\text { Cannulation success } \\
\text { global (\%) }\end{array}$ & Complications (\%) & NKF by group (\%) \\
\hline Harewood et al. [11] & 253 & $\begin{array}{l}\text { Four of } 50 \\
\text { and the last } \\
\text { with } 53\end{array}$ & na & $88-89-90-88-98^{1}$ & $12-18-20-12-14^{2}$ & $13-12-10-10-9^{3}$ \\
\hline Rollhauser et al. [14] & 68 & $\begin{array}{l}\text { Two } \\
\text { (22 and 46) }\end{array}$ & $64-74^{4,1}$ & $86-98^{1}$ & na & $4.7-6.3^{1}$ \\
\hline Fukatsu et al. [15] ${ }^{*}$ & 104 & $\begin{array}{l}\text { Two } \\
\text { (41 and 63) }\end{array}$ & $80-95^{5}$ & $90-98^{1}$ & $10-16^{1}$ & $15-20^{1}$ \\
\hline Akaraviputh et al. [16] ${ }^{* *}$ & 200 & Four of 50 & $88-86-94-82^{2}$ & $94-96-94-92^{2}$ & $30-30-10-10^{3}$ & na \\
\hline Robinson et al. [17] & 150 & Six of 25 & $64-68-76-80-76-84^{4,5}$ & $84-84-88-88-88-92^{1}$ & $8-8-16-4-0-4^{3}$ & na \\
\hline
\end{tabular}

na, non-available; * classic precut ${ }^{* *}$ NKF and classic precut.

${ }^{1}$ positive trend

2 no trend

${ }^{3}$ negative trend

${ }^{4} p<0.05$.

${ }^{5}$ positive trend and $P<0.05$

and once again, there is no stable pattern for a lower rate of pancreatitis as experience is accumulated. EA and EB had a decrease in the rate of pancreatitis from $10 \%$ to $5 \%$ (between Group 1 and Group 2), and from 7.5\% to 5\% (between Group 2 and Group 3), respectively. Nonetheless, EC demonstrated an increase from $7.5 \%$ to $10 \%$ in the last group.EA and EB had the lowest rate of pancreatitis (5\%) in the last 40 patients submitted to NKF, while EC had the highest with $10 \%$. Although the number of patients is reduced, one possible explanation for the higher rates of pancreatitis for EC may result from the technique of cannulation employed. EC confirmed the duct through injection of contrast, while the other two inserted the wire deep in the duct before injection. This could increase the proportion of patients with inadvertent injection of contrast to the main pancreatic duct, which is per se a risk factor for post-ERCP pancreatitis, not specifically related to the NKF technique.

The results from other studies are diverse, Harewood et al. reported that the adverse events did not diminish over time and Fukatsu et al. reported an increase from $10 \%$ to $16 \%$ ( Table 3 ) $[2,11,15,19]$. On the other hand, Robinson et al. reported a decrease in adverse events over time, which may be explained by the increased use of pancreatic stents in the latter groups ( $\square$ Table 3$)[16,17,20,21]$. One may argue that the nonexistence of a clear decline in the complication rates results from the use of precut only after a difficult biliary cannulation. It is interesting to note that the precut procedures applied to all of the patients encompassed in the precut training reports were only performed following a difficult biliary cannulation. As this procedure is in itself a risk factor for post-ERCP adverse events, in particular pancreatitis, it could partially offset the positive effect of experience [29]. Another possible explanation is an inherent baseline complication rate associated with the precut that cannot be diminished by experience, as Harewood et al. suggest [11].

Our study, similar to others, indicates that a skilled endoscopist with the proper cognitive skills may safely and effectively learn the needle-knife precut technique without supervision. Nonetheless, it must be emphasized that these endoscopists are not a sample representing average endoscopists, but rather a specific group of professionals who perform a large volume of ERCPs per year (>200/year). Although all endoscopists from the published studies initiated the technique without previous hands-on training, it is strongly advised that, given the potential medical legal implications, a fellowship should be set up in an ERCP center with a liberal use of the technique. Furthermore, as we cannot predict the innate skills of an endoscopist ab initium, a formal training period is recommended. The studies published often suggest 40 to $50 \mathrm{NKF}$ as an adequate number of precuts for training, given that most endoscopists after this threshold report a needle-knife precut success above $70 \%[5,11,14,16,17]$.

Although suggesting a minimum number of precuts for assessing proficiency in NKF is problematic, we propose 20 NKFs (and not 40 or 50 ) for the first moment of assessment. This number takes into consideration the existence of some endoscopists who become skillful in the technique in an earlier phase of their learning curve, as demonstrated in our study by EA and EC. Given that few centers in the world perform more than 40 precuts per year, a full-time or part-time half program is required. Clearly, the training in NKF should only be offered to endoscopists who achieve a selective biliary cannulation above $80 \%$ using a standard approach. During the training period, the trainee should be able to master the more complex aspects of the precut, such as the identification of the correct axis of the incision and the recognition of the CBD duct after unroofing the papilla $[1,16]$.

A major limitation of this study results from the limited number of endoscopists (3) included and its retrospective design, which hampers the validity of the conclusions. As NKF is generally carried out in less than 40 patients per year in any one center, only a multicenter study, possibly during several years, could enroll a sufficient number of patients to evaluate the learning curve [16]. Nonetheless, the insights from the data presented together with the existing studies could contribute toward the establishment of evidence-based recommendations and the design of prospective studies addressing the issue.

In summary, precut with few adverse events is easily learned by a skillful endoscopist with the proper cognitive skills performing a high number of ERCPs. While some endoscopists could begin on their own because of their innate skills, all should have a formal training period as we cannot predict these innate skills in advance. However, as the focus of ERCP in the twenty-first century should be on quality, the precut procedure should be an obligatory issue in the ERCP training curriculum for all future interventional endoscopists. We propose a minimum of $20 \mathrm{NKF}$ precuts to first attest a trainee's competence in this procedure.

\section{Competing interests: None}


Institutions

${ }^{1}$ Department of Gastroenterology, Hospital of Santa Luzia, Viana do Castelo, Portugal

${ }^{2}$ Life and Health Sciences Research Institute (ICVS), School of Health Sciences, University of Minho, Braga, Portugal

${ }^{3}$ ICVS/3B's, PT Government Associate Laboratory, Guimarães/Braga, Portugal

${ }^{4}$ Centre for Research in Health Technologies and Information Systems (CINTESIS), Faculty of Medicine, University of Porto, Porto, Portugal

5 Department of Gastroenterology, IPO Porto, Portugal

${ }^{6}$ Department of Gastroenterology, Hospital Braga, Braga, Portugal

\section{References}

1 Freeman $M L$, Guda NM. ERCP cannulation: a review of reported techniques. Gastrointest Endosc 2005; 61: 112-125

2 Bjorkman DJ, Popp JW. Measuring the quality of endoscopy. Gastrointest Endosc 2006; 63: $1-2$

3 Freeman ML. Adverse outcomes of endoscopic retrograde cholangiopancreatography. Rev Gastroenterol Disord 2002; 2: 147-168

4 Petersen BT. ERCP outcomes: defining the operators, experience, and environments. Gastrointest Endosc 2002; 55: 953 - 958

5 Bruins Slot W, Schoeman MN, DiSario JA et al. Needle-knife sphincterotomy as a precut procedure: a retrospective evaluation of efficacy and complications. Endoscopy 1996; 28: 334 - 339

6 Testoni PA, Testoni S, Giussani A. Difficult biliary cannulation during ERCP: How to facilitate biliary access and minimize the risk of postERCP pancreatitis. Dig Liver Dis 2011; 43: 596-603

7 Sriram PVJ, Rao GV, Nageshwar Reddy D. The precut - when, where and how? A review Endoscopy 2003; 35: 24-30

8 Gong B, Hao L, Bie L et al. Does precut technique improve selective bile duct cannulation or increase post-ERCP pancreatitis rate? A meta-analysis of randomized controlled trials Surg Endosc 2010; 24: 670 680

9 Cennamo V, Fuccio L, Zagari RM et al. Can early precut implementation reduce endoscopic retrograde cholangiopancreatography-related complication risk? Meta-analysis of randomized controlled trials Endoscopy 2010; 42: 381 - 388

10 Lopes L, Dinis-Ribeiro M, Rolanda C. Early precut fistulotomy for biliary access: time to change the paradigm of "the later, the better?" Gastrointest Endosc 2014; 80: 634-641

11 Harewood GC, Baron TH. An assessment of the learning curve for precut biliary sphincterotomy. Am J Gastroenterol 2002; 97: 1708-1712

12 Chutkan RK, Ahmad AS, Cohen J et al. ERCP core curriculum. Gastrointest Endosc 2006; 63: 361 - 376

13 Ang TL, Cheng J, Khor JLC et al. Guideline on training and credentialing in endoscopic retrograde cholangiopancreatography. Singapore Med J $2011 ; 52: 654-657$
14 Rollhauser C, Johnson M, Al-Kawas FH. Needle-knife papillotomy: a helpful and safe adjunct to endoscopic retrograde cholangiopancreatography in a selected population. Endoscopy 1998; 30: 691 -696

15 Fukatsu H, Kawamoto H, Harada $R$ et al. Quantitative assessment of technical proficiency in performing needle-knife precut papillotomy. Surg Endosc 2009; 23: 2066-2072

16 Akaraviputh $T$, Lohsiriwat $V$, Swangsri $J$ et al. The learning curve for safety and success of precut sphincterotomy for therapeutic ERCP: a single endoscopist's experience. Endoscopy 2008; 40: 513-516

17 Robison LS, Varadarajulu S, Wilcox CM. Safety and success of precut biliary sphincterotomy: Is it linked to experience or expertise? World J Gastroenterol 2007; 13: 2183 - 2186

18 Cotton PB, Eisen GM, Aabakken $L$ et al. A lexicon for endoscopic adverse events: report of an ASGE workshop. Gastrointest Endosc 2010; 71: $446-454$

19 Johanson JF, Cooper G, Eisen GM et al. Quality assessment of ERCP. Endoscopic retrograde cholangiopancreatography. Gastrointest Endosc 2002; 56: $165-169$

20 Cotton PB, Lehman G, Vennes J et al. Endoscopic sphincterotomy complications and their management: an attempt at consensus. Gastrointest Endosc 1991; 37: 383 - 393

$21 \mathrm{NIH}$. state-of-the-science statement on endoscopic retrograde cholangiopancreatography (ERCP) for diagnosis and therapy. NIH Consens State Sci Statements 2002; 19: 1 - 26

22 ASGE Standards of Practice Committee. Anderson MA, Fisher L, Jain R et al. Complications of ERCP. Gastrointest Endosc 2012; 75: 467 - 473

23 Ang TL, Kwek ABE, Lim KBL et al. An analysis of the efficacy and safety of a strategy of early precut for biliary access during difficult endoscopic retrograde cholangiopancreatography in a general hospital. J Dig Dis 2010; 11: $306-312$

24 Siegel JH. Precut papillotomy: a method to improve success of ERCP and papillotomy. Endoscopy 1980; 12: 130-133

25 Huibregtse K, Katon RM, Tytgat GN. Precut papillotomy via fine-needle knife papillotome: a safe and effective technique. Gastrointest Endosc 1986; 32: $403-405$

26 Kasmin FE, Cohen D, Batra S et al. Needle-knife sphincterotomy in a tertiary referral center: efficacy and complications. Gastrointest Endosc 1996; 44: $48-53$

27 Kaffes AJ, Sriram PVJ, Rao GV et al. Early institution of pre-cutting for difficult biliary cannulation: a prospective study comparing conventional vs. a modified technique. Gastrointest Endosc 2005; 62: 669 674

28 Rabenstein T, Ruppert T, Schneider HT et al. Benefits and risks of needleknife papillotomy. Gastrointest Endosc 1997; 46: 207 - 211

29 Dumonceau J-M, Andriulli A, Devière J et al. European Society of Gastrointestinal Endoscopy (ESGE) Guideline: prophylaxis of post-ERCP pancreatitis. Endoscopy 2010; 42: $503-515$ 